\title{
How Autonomy is Used in Information Systems Research: Status Quo and Prospective Opportunities
}

\author{
Sebastian Weber \\ University of Siegen, Germany \\ sebastian.weber@student.uni-siegen.de \\ Frederike Marie Oschinsky \\ University of Siegen, Germany \\ frederike.oschinsky@uni-siegen.de
}

\author{
Michael Klesel \\ University of Siegen, Germany \\ University of Twente, The Netherlands \\ michael.klesel@uni-siegen.de \\ Bjoern Niehaves \\ University of Siegen, Germany \\ bjoern.niehaves@uni-siegen.de
}

\begin{abstract}
Autonomy is a pivotal concept that allows researchers to investigate important aspects such as job-related outcomes in Information Systems (IS) research. With the increase of mobile technologies, autonomy is increasingly gaining importance. Given the growing body of research in this area, this research presents the results of a systematic literature review. Our results show in detail how autonomy has been used and identifies fruitful avenues for future research. Specifically, we suggest that future research should contextualize autonomy to give it a central theoretical significance for IS research. Moreover, future research should also acknowledge the multidimensional facets of autonomy to enhance its explanatory power.
\end{abstract}

\section{Introduction}

Autonomy has been used for at least three decades (e.g., [52]) to investigate important phenomena that are related to Information Systems (IS) research. A major reason for the great interest in autonomy relates to the fact that having freedom is a fundamental human need. Moreover, arguments have been made that Information Technology (IT) has a significant impact on how individuals perceive autonomy [39] and vice versa, how perceived autonomy influences IT use [2]. Consequently, numerous scholars have conceptualized autonomy to explore IS-related phenomena. To that end, autonomy has been applied to the individual, group, and organizational level. Moreover, it has been used to describe individual characteristics, job characteristics, or design aspects. Therefore, the concept of autonomy can be considered a pivotal construct for IS research. Figure 1 also highlights that autonomy, based on our review, enjoys continued and growing attention in IS research.

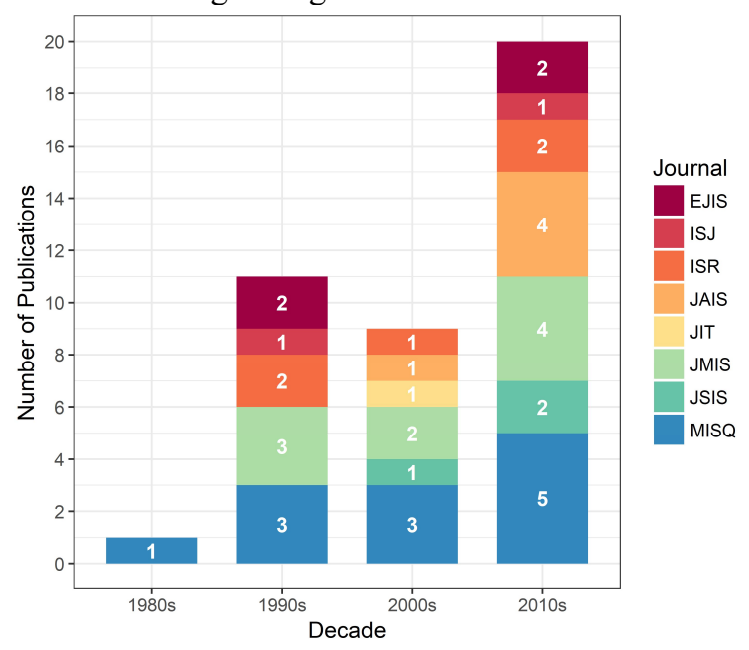

Figure 1. Autonomy-related research in the 'basket of eight' per decade

Due to the high interest in autonomy, there is a wide range of how the concept is used. While some scholars use it as an overall job characteristic [2], others use it to conceptualize specific dimensions such as decision-making autonomy [3]. Similarly, autonomy has been used as a unidimensional construct as well as a multidimensional construct [30]. As a consequence, there is a broad spectrum of perspectives to study autonomy.

While the great interest in autonomy has significantly contributed to extend the current body of knowledge, it also led to an ambiguity in terms of the way the concept can be used. In specific, it remains unclear which domains to conceptualize autonomy exist and what the existing are may lacking to provide a better representation and explanation in the future. 
Since this is a potential threat for theory development, our research objective is to provide a systematic overview of how autonomy has been used in IS research so far.

By addressing our objective, our contribution is twofold: First, we aim to provide a systematic overview of the used autonomy conceptualizations. To do this, we analyze the concept in terms of what it captures (i.e., the unit of analysis, the dimensionality, the operationalization, and the technologyrelationship). Second, we want to identify prospective opportunities on how to study autonomy in IS. Considering the multitude of used operationalizations, we want to emphasize the fact that autonomy is not only relevant to conceptualize job characteristics, but can also be adopted for technology-related issues. In specific, we highlight the occasion to consider technology-autonomy as a fruitful concept (i.e., a concept that recognizes technology specific choices) for future research.

In order to address our objectives, the remainder is structured as follows: In section two, we briefly review the role of autonomy in general and in IS research. After that, we present our methodological approach in detail. In section four, we present our results. We reflect and discuss our findings in section five. We conclude by highlighting the limitations of our study and by providing some avenues for future research.

\section{The Role of Autonomy in IS Research}

Etymologically, the concept of autonomy originates from the ancient Greek terms "autos" (self) and "nomos" (rule or law), which refers to the idea that citizens can make their own rules [16]. Based on its generic nature, the concept of autonomy has been studied at various levels in several disciplines, including philosophy (e.g., $[12,16])$, psychology (e.g., $[14,20,27,53])$, organizational sciences (e.g., [39,54]), and information systems (IS) research (e.g., [1,2,23,42]). Consequently, manifold conceptualizations, operationalization, and outcomes emerged.

In psychology, autonomy is a well-known construct since it is a fundamental aspect of influential theories such as the job characteristics model (JCM) [20] and the self-determination theory (SDT) [14]. The JCM links several job design characteristics, such as job autonomy to explain job responses (e.g., satisfaction, turnover) [19]. Hackman and Oldham define job autonomy as "the degree to which the job provides substantial freedom, independence, and discretion to the employee in scheduling the work and in determining the procedures to be used in carrying it out" [19]. In particular, results of a JCM meta-analysis provide evidence that a work design which features job autonomy yields positive employee attitudinal outcomes [18]. In the case of SDT, which is a theory of human motivation, autonomy is one of three innate psychological needs that foster self-motivation [51]. Within this theory, autonomy refers to "not to being independent, detached, or selfish but rather to the feeling of volition that can accompany any act, whether dependent or independent, collectivist or individualist" [51]. Conditions which support this feeling of autonomy promote higher intrinsic motivation and improved personal well-being [51].

In contrast to these positive findings, other studies also highlight critical issues related to autonomy. Most notably, studies from organizational sciences report an autonomy paradox [39,54]. The autonomy paradox reflects that the introduction of mobile email devices in the work context first increases the perceived autonomy of an individual. However, over time, when the device use is collectively adapted, this sense of autonomy decreases, due to the pressure of always being available [39].

Previous IS literature examined autonomy in various research streams. Literature often uses the JCM (e.g., [43,55]) and SDT (e.g., [26,28]) in an ISspecific context. They often integrate the autonomy construct of these theories in new theories, such as work exhaustion theory [42], social exchange theory [61], theory of effective use [34], field theory [17] as well as task closure theory [46]. In most cases, these studies integrate the construct of autonomy of the JCM. Hence, autonomy is often used as a job characteristic to explain important IS job-related outcomes, including innovation behavior [2], jobsatisfaction $[43,55]$, or turnover $[1,42]$. Apart from explicit conceptualizations of autonomy, IS research also uses several concepts relating to autonomy. For instance, they utilize the concept of task authority [52], perceived locus of causality [37], outcome control $[38,45]$, or centralization [29].

Based on the prevalence of autonomy in IS research, various perspectives have been taken to investigate autonomy. Nevertheless, a systematic synthesis of how autonomy can be used, e.g., what entities have been analyzed, or what the pivotal focus of autonomy(-related) concepts is, has not been conducted so far. Against this background, we address this shortcoming and provide a structured literature analysis of autonomy in IS research.

\section{Methodology}

\subsection{Method selection and data collection}


In order to examine how the concept of autonomy has been used in IS research, we conducted a structured literature review $[5,57,58,60]$ and followed a proposed five-step procedure as suggested by vom Brocke et al. [57]:

1) definition of review scope: In the first step, we used the taxonomy of Cooper [13] to define our review scope. According to this taxonomy, we focus on how the concept of autonomy is operationalized. The goal of our review is synthesizing and integrating findings of prior work on autonomy to purvey a status quo and to give advice on how scholars can further extend the current body of knowledge. Since we are interested in analyzing the construct of autonomy in this review, we organize it methodologically and conceptually (i.e., synthesizing by similar measurement approaches and same abstract ideas). To achieve this goal, we espouse a neutral perspective to inform general and specialized scholars in the field of autonomy-related IS research. Furthermore, our review aims to cover pivotal autonomy-related research for the IS discipline by including the Association for Information Systems (AIS) senior scholars' basket of journals (known as the 'basket of eight') [4]. We focused on these impactful outlets because we believe that they cover a substantial body of knowledge within the IS field.

2) conceptualization of topic: In the second step, it is suggested to give a broad conception of the topic and to identify potential research areas. Therefore, we give a brief overview of autonomy in general as well as in IS research in specific in the previous chapter. We identified a gap which we want to address with this review.

3) literature search: Step three involves the literature search. As aforementioned, we focused our search on the 'basket of eight' and therefore used the databases Web of Science, ScienceDirect, and EBSCOhost, which provided us access to these journals. To find relevant papers, we chose the search term 'autonomy' because it incorporates several variations (e.g., job autonomy, task autonomy) and searched within the title, abstract and in the keywords/subject without limitations regarding the publication date. The literature search was conducted in November 2018 and yielded 48 papers.

Papers with a scope not related to our research were excluded. Hence, all abstracts, titles, and keywords were first scrutinized to check their suitability. The examination yielded the exclusion of two papers as they did not mention autonomy or

\footnotetext{
${ }^{1}$ Note that MacKenzie et al. [36] also highlight other aspects.

Since our data is mostly cross-sectional, we are not able to
}

related terms $[35,47]$. This led to a sample of 46 papers for a complete reading. After reading each paper thoroughly, further papers that mentioned autonomy only on a surface, but not as a focal concept in their research, were also excluded [21,41,48,50,59].

In summary, we identified and investigated 41 papers in more detail. The search, exclusion, and further investigation were performed by at least two of the authors. If differences arose, they were discussed in the group and solved together. Table 1 provides an overview of the identified papers. Since the primary objective of this paper is the investigation of autonomy and its operationalization, we only consider quantitative studies and their measurements in the subsequent steps 4) literature analysis and synthesis and 5) research agenda. Thus, we included 27 papers for our detailed analysis, which is presented and discussed in the following.

\section{Table 1. Distribution of considered papers per outlet}

\begin{tabular}{lcccccc}
\hline Outlet & \multicolumn{7}{c}{ Identified papers } \\
\cline { 2 - 7 } & $\begin{array}{c}\text { quali- } \\
\text { tative }\end{array}$ & $\%$ & $\begin{array}{c}\text { quanti- } \\
\text { tative }\end{array}$ & $\%$ & $\Sigma$ & $\%$ \\
\hline EJIS & 4 & 10 & 0 & 0 & 4 & 10 \\
ISJ & 0 & 0 & 2 & 5 & 2 & 5 \\
ISR & 3 & 7 & 2 & 5 & 5 & 12 \\
JAIS & 3 & 7 & 2 & 5 & 5 & 12 \\
JIT & 1 & 2 & 0 & 0 & 1 & 2 \\
JMIS & 0 & 0 & 9 & 22 & 9 & 22 \\
JSIS & 1 & 2 & 2 & 5 & 3 & 8 \\
MISQ & 2 & 5 & 10 & 24 & 12 & 29 \\
\hline Total & $\mathbf{1 4}$ & $\mathbf{3 4}$ & $\mathbf{2 7}$ & $\mathbf{6 6}$ & $\mathbf{4 1}$ & $\mathbf{1 0 0}$ \\
\hline
\end{tabular}

\subsection{Data analysis}

For a systematic analysis of the literature on autonomy [60], we develop a framework that covers the fundamental properties of a construct. Drawing from MacKenzie et al. [36], we include four different aspects that are explained in the following ${ }^{1}$ :

Entity: reflects the unit of analysis that is used to investigate autonomy. The entity can be either the individual level, the group level, or the organizational level. We classified each study based on the underlying measurement items. For instance, items like "I control the content of my job." [2] indicate that autonomy is investigated on an individual level. In contrast, authors who indicate that organizationallevel constructs were measured (e.g., [49]) are classified accordingly.

investigate, e.g., "stability over time" thoroughly. Thus, we limit this review on four crucial aspects of a construct. 
Dimensionality: indicates whether a construct is measured in a unidimensional manner or by means of multiple dimensions. To evaluate the dimensionality, we look at the constructs and items. Most of the analyzed research measures autonomy with one scale and without any sub-dimensions [1,42,43]. Those studies are classified as unidimensional. In contrast, authors who included multiple dimensions of autonomy (e.g., scheduling autonomy, work-method autonomy, decision-making autonomy as proposed by Ye and Kankanhalli [62]) are classified accordingly.

Construct: refers to the operationalization of a construct. Previous literature often adopts the concept of autonomy for a specific context. Thus, they slightly differ from the general notion of autonomy. For instance, Durcikova et al. [15] use "climate for autonomy" instead of job autonomy to examine if employees perceive the organizational climate as autonomous. However, since the measurement items are aligned with the general notion of (job-)autonomy (i.e., "I schedule my own work activities.") [15], they are categorized in the general section. In contrast, Karahanna et al. [26] measure autonomy as an innate psychological need, originating from the SDT, which operationalizes autonomy with another focal point than (job-)autonomy. While the general notion reflects autonomy regarding work-tasks, the satisfaction of the need of autonomy describes a "subjective experience of psychological freedom and choice during activity engagement" (e.g., one can also feel satisfaction of the need of autonomy when he is dependent on others) [10]. Thus, we distinguish constructs that differ in their meaning as well as operationalization and clustered similar ones.

Technology-relationship: reflects how autonomy is used in order to make it relevant for the IS discipline. For that purpose, we distinguish a direct and indirect relationship towards IT. A direct relationship is given when the construct itself is adapted for an IS-specific context. For instance, data resource management (DRM)-related autonomy [24] is considered a direct relationship. This becomes most evident in terms of the measurement items, which are likewise adopted for the IS context (e.g., a free selection of hardware) [24]. In contrast, an indirect relationship exists when the IS-context is given via the structural model (e.g., [43]) or via the study sample (e.g., IS professional as shown in [42]).

\section{Results}

The results of our analysis are summarized in Table 2 and Table 3 . They highlight that the primary entity of analysis is the individual level (74\%), whereas research on the group- (15\%) and organizational level $(11 \%)$ has been of less interest. $73 \%$ are classified as autonomy in general, whereas $27 \%$ are contextualized constructs. Regarding the dimensionality, the majority recognizes autonomy as a unidimensional construct (78\%). Only $22 \%$ consider autonomy as a multidimensional construct. A direct technology-relationship was given in $15 \%$ of the autonomy constructs, while the other research does this indirectly via an IS context (52\% indirect via the structural model and 33\% indirect via the sample).

Table 2. Quantitative results

\begin{tabular}{lll}
\hline Property & Classification & $\mathbf{\%}$ \\
\hline Entity & Individual & 74 \\
& Group & 15 \\
& Organizational & 11 \\
Construct & Autonomy & 73 \\
& Contextualized construct & 27 \\
Dimensionality & Unidimensional & 78 \\
& Multidimensional & 22 \\
Technology- & Direct & 15 \\
relationship & Indirect via theory & 52 \\
& Indirect via sample & 33 \\
\hline
\end{tabular}

Studies using autonomy on the individual level are mainly concerned with job-related aspects. For instance, previous studies investigated job satisfaction $[22,23,43,55]$, job performance [46] and turnover intention $[1,42]$ of IS employees. This has also been done in an IT context, e.g., through the investigation during the implementation of an Enterprise Resource Planning System [43]. However, none of the unidimensional autonomy constructs had a direct relationship towards IT. In contrast, the two papers, that recognize autonomy as a multidimensional construct, measure autonomy with a focus on technology. For instance, Ye and Kankanhalli [62] show the impact of design autonomy on the user's innovation quantity. To this end, they measure design autonomy as a three-faceted construct, whereby each of the dimensions (i.e., scheduling autonomy, workmethod autonomy, decision-making autonomy) is centered on free technology-specific choices (e.g., choosing the time to develop an application, freedom to choose a method to design applications, choosing the application one would like to develop). Their results reveal that work-method autonomy and decision-making autonomy positively support the quantity of newly developed [62]. 
Research on the group level used multidimensional autonomy constructs more often compared to unidimensional constructs. The constructs mostly aim to measure team autonomy. However, only the unidimensional construct measures team-autonomy with a focus on technology. In specific, the authors show that agile software development teams are more efficient in responding to users' requirement changes when they have more autonomy in terms of technology (e.g., choosing the technology and tools to develop) [33]. Besides the positive effects, there are also seem to be adverse effects that reduce the degree of response extensiveness (i.e., they responded less to user requirements [33]. The multidimensional team autonomy constructs with two facets measure autonomy with an indirect technology-relationship, as they study IS employees. Both research results indicate that providing teams with autonomy yields positive outcomes in the form of better software project quality [38] and improved quality of work life and performance [25]. The other multidimensional construct, which takes into account a technologyrelationship, has a focus on DRM-related autonomy [24]. The authors' analysis reveals that this technology-specific autonomy should be adjusted to the organizational settings (i.e., a high need of centralization requires a limited autonomy of local units, while a need for decentralization requires a high degree of autonomy) to achieve high DRM success [24].

On the organizational level, the term autonomy generally expresses how much power the organization has in relation to its environment. The majority measures autonomy unidimensionally. However, none of the research papers measured autonomy with a focal point on technology. For instance, the results of Roberts et al. [49] suggest that organizations that grant autonomy to their IS managers, take more benefit of innovative IS use, because these managers have the opportunity to create more diverse ideas and thus also improve economic gain.

Table 3. Overview of the results

\begin{tabular}{|c|c|c|c|c|}
\hline Entity & Dimensionality & Construct & Technology-relationship & References \\
\hline \multirow{7}{*}{ 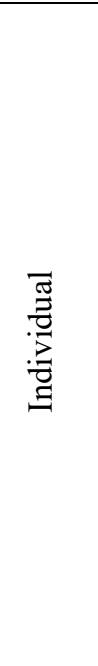 } & \multirow{5}{*}{ Uni } & \multirow{2}{*}{$\begin{array}{l}\text { (Job-) } \\
\text { Autonomy }\end{array}$} & $\begin{array}{l}\text { Indirect via structural model } \\
\text { (e.g., part of TAM) }\end{array}$ & $\begin{array}{l}{[2,15,17,34,43,52,} \\
56,61]\end{array}$ \\
\hline & & & $\begin{array}{l}\text { Indirect via sample (e.g., IT } \\
\text { consultants) }\end{array}$ & {$[1,22,23,42,46,55]$} \\
\hline & & $\begin{array}{l}\text { Satisfaction of Needs for } \\
\text { Autonomy }\end{array}$ & Indirect via structural model & {$[26,28]$} \\
\hline & & $\begin{array}{l}\text { Perceived Locus of } \\
\text { Causality }\end{array}$ & Indirect via structural model & [37] \\
\hline & & $\begin{array}{l}\text { Decision-Making } \\
\text { Autonomy }\end{array}$ & Indirect via structural model & [3] \\
\hline & \multirow[b]{2}{*}{ Multi } & Design Autonomy & Direct via construct & [62] \\
\hline & & $\begin{array}{l}\text { Autonomy for Strategic } \\
\text { Systems Planning }\end{array}$ & Direct via construct & [40] \\
\hline \multirow{3}{*}{ 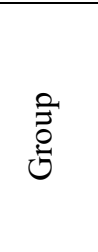 } & Uni & Team Autonomy & Direct via construct & {$[33]$} \\
\hline & \multirow[t]{2}{*}{ Multi } & Team Autonomy & $\begin{array}{l}\text { Indirect via sample } \\
\text { (software development } \\
\text { teams) }\end{array}$ & {$[25,38]$} \\
\hline & & DRM-Related Autonomy & Direct via construct & [24] \\
\hline \multirow{3}{*}{ 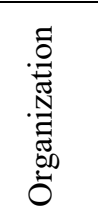 } & \multirow{2}{*}{ Uni } & Centralization & Indirect via structural model & [29] \\
\hline & & Organizational Autonomy & Indirect via structural model & [49] \\
\hline & Multi & $\begin{array}{l}\text { Outcome Control / } \\
\text { Decentralization }\end{array}$ & $\begin{array}{l}\text { Indirect via sample } \\
\text { (software firms) }\end{array}$ & {$[45]$} \\
\hline
\end{tabular}




\section{Discussion}

Our results show that the concept of autonomy is frequently operationalized as a unidimensional concept. In the domain of job-related research, it commonly reflects an overall job autonomy. While this approach contributes to a better understanding of previously unknown relationships, it is also limited due to the disregard of other dimensions. For example, it prevents the identification of the individual influences of the different autonomy facets. This in turn leads to the fact that no concrete actions that are important for practice can be derived. The large number of studies at this level also show that employees value autonomy as it is linked to several important outcomes such as organizational commitment [1] or job satisfaction [22]. Furthermore, with regard to IS-specific outcomes it is linked to innovation behavior $[2,15]$ or IT satisfaction [31]. Since IS employees and innovative IS behavior are crucial resources for business success, we argue that it is beneficial to take a closer look at the different facets of autonomy. Several studies by Breaugh [6-9] also continuously support the multi-dimensionality of autonomy. Therefore, it is promising to conceptualize autonomy not as a single-dimensional construct but as a multi-dimensional one to increase the explanatory power of future theories. Current studies already including multiple dimensions (e.g., [62]) show that the inclusion of different dimensions is vital for a better understanding of IS-related phenomena. Hence, we suggest acknowledging autonomy as a multidimensional facet in future research.

Autonomy in the proper sense is often not ISspecific. Still, it is not surprising that the concept itself has widely been used to extend IS theories $[24,33,40,62]$. However, in light of the rich concept of technology use [11], there are several undeveloped opportunities to contextualize autonomy for the IS discipline. For instance, based on the increasing dissemination of mobile technologies, autonomy can be adapted to reflect the freedom to choose or the freedom to use a specific technology. Initial efforts in this direction have already been made. For example, Murray and Häubl [44] show the impact of freedom of choice in cases of alternative interfaces. Thus, this approach is promising in terms of an IS-specific conceptualization of autonomy (i.e., technology autonomy). The results offer an initial starting point as they examine how the construct of autonomy has been used in prior research.

Our review demonstrates that the concept of autonomy is well suited to be used for different units of analysis. In specific, there is sufficient literature that uses autonomy on an individual, group, and organizational level. Despite this fact, most research uses autonomy on an individual level. Acknowledging the strong influence of occupational theories, including the JDC [19] and the SDT [14] this is not surprising. However, we argue that IS research still leaves great potential out of sight. Specifically, with a high degree of autonomy on the individual level [39], it is reasonable to assume an impact on the group and the organizational level [32]. Consequently, we suggest using autonomy on the group and organizational level as well as taking a cross-level perspective.

\section{Limitations and Outlook}

This research has several important limitations. First, for this review, we limited our scope on a few very impactful outlets. To make this review more comprehensive, future research should include more outlets (e.g., conferences). Second, we identified several promising avenues for future research that have not been investigated in detail so far. Hence, further empirical insights are required to support or reject our findings. In specific, future research should develop a construct to measure IS-specific autonomy and investigate the effects of it on outcome variables such as job satisfaction or IT satisfaction. Third, it is also important to report that this study has primarily been investigated on a measurement level. Whereas this can be most useful for quantitative research, it is limited regarding qualitative research. Consequently, future research could also investigate and synthesize the results of research that have been conducted qualitatively. Alternatively, future research could investigate the effects of autonomy utilizing a metaanalysis to show the most important effects. Finally, we suggest that future research should conceptualize and evaluate a multi-dimensional measurement instrument that includes commonly used dimensions of autonomy as well as new dimensions such as instrument autonomy in order to make it more relevant for IS research.

\section{References}

[1] Ahuja, M. K., Chudoba, K. M., Kacmar, C. J. et al., "IT Road Warriors: Balancing Work-Family Conflict, Job Autonomy, and Work Overload to Mitigate Turnover Intentions," MIS Quarterly, vol. 31, no. 1, 2007, pp. 1-17.

[2] Ahuja, M. K. and Thatcher, J. B., "Moving Beyond Intentions and Toward the Theory of Trying: Effects of Work Environment and Gender on Post-Adoption Information Technology Use," MIS Quarterly, vol. 29, no. 3, 2005, pp. 427-459. 
[3] Andersen, T. J., "Information Technology, Strategic Decision Making Approaches and Organizational Performance in Different Industrial Settings," The Journal of Strategic Information Systems, vol. 10, no. 2, 2001, pp. 101-119.

[4] Association of Information Systems, "Senior Scholars' Basket of Journals," https://aisnet.org/page/SeniorScholarBasket, Accessed January 31, 2019.

[5] Boell, S. K. and Cecez-Kecmanovic, D., "On Being 'Systematic' in Literature Reviews in IS," Journal of Information Technology, vol. 30, no. 2, 2015, pp. 161-173.

[6] Breaugh, J. A., "The Measurement of Work Autonomy," Human Relations, vol. 38, no. 6, 1985, pp. 551-570.

[7] Breaugh, J. A., "The Work Autonomy Scales: Additional Validity Evidence," Human Relations, vol. 42, no. 11,1989 , pp. 1033-1056.

[8] Breaugh, J. A., "Further Investigation of the Work Autonomy Scales: Two Studies," Journal of Business and Psychology, vol. 13, no. 3, 1999, pp. 357-373.

[9] Breaugh, J. A. and Becker, A. S., "Further Examination of the Work Autonomy Scales: Three Studies," Human Relations, vol. 40, no. 6, 1987, pp. 381-399.

[10] Broeck, A., Vansteenkiste, M., Witte, H. et al., "Capturing Autonomy, Competence, and Relatedness at Work: Construction and Initial Validation of the WorkRelated Basic Need Satisfaction Scale," Journal of Occupational and Organizational Psychology, vol. 83, no. 4, 2010, pp. 981-1002.

[11] Burton-Jones, A. and Straub, D. W., "Reconceptualizing System Usage: An Approach and Empirical Test," Information Systems Research, vol. 17, no. 3, 2006, pp. 228-246.

[12] Castoriadis, C., Philosophy, Politics, Autonomy, Oxford University Press, New York, 1991.

[13] Cooper, H. M., "Organizing Knowledge Syntheses: A Taxonomy of Literature Reviews," Knowledge in Society, vol. 1, no. 1, 1988, pp. 104-126.

[14] Deci, E. L., Connell, J. E., and Ryan, R. M., "SelfDetermination in a Work Organization," Journal of Applied Psychology, vol. 74, no. 4, 1989, pp. 580-590.

[15] Durcikova, A., Fadel, K. J., Butler, B. S. et al., "Knowledge Exploration and Exploitation: The Impacts of Psychological Climate and Knowledge Management System Access," Information Systems Research, vol. 22, no. 4, 2011, pp. 855-866.

[16] Dworkin, G., The Theory and Practice of Autonomy, Cambridge University Press, Cambridge, 1988.
[17] Elie-Dit-Cosaque, C., Pallud, J., and Kalika, M., "The Influence of Individual, Contextual, and Social Factors on Perceived Behavioral Control of Information Technology: A Field Theory Approach," Journal of Management Information Systems, vol. 28, no. 3, 2011, pp. 201-234.

[18] Fried, Y. and Ferris, G. R., "The Validity of the Job Characteristics Model: A Review and Meta-Analysis," Personnel Psychology, vol. 40, no. 2, 1987, pp. 287-322.

[19] Hackman, J. R. and Oldham, G. R., "Development of the Job Diagnostic Survey," Journal of Applied Psychology, vol. 60, no. 2, 1975, pp. 159-170.

[20] Hackman, J. R. and Oldham, G. R., "Motivation Through the Design of Work: Test of a Theory," Organizational Behavior and Human Performance, vol. 16, no. 2, 1976, pp. 250-279.

[21] Howard, M., "Collaboration and the '3DayCar': A Study of Automotive ICT Adoption," Journal of Information Technology, vol. 20, no. 4, 2005, pp. 245-258.

[22] Igbaria, M. and Baroudi, J. J., “A Short-Form Measure of Career Orientations: A Psychometric Evaluation," Journal of Management Information Systems, vol. 10, no. 2, 1993, pp. 131-154.

[23] Igbaria, M., Greenhaus, J. H., and Parasuraman, S., "Career Orientations of MIS Employees: An Empirical Analysis," MIS Quarterly, vol. 15, no. 2, 1991, pp. 151169.

[24] Jain, H., Ramamurthy, K., Ryu, H.-S. et al., "Success of Data Resource Management in Distributed Environments: An Empirical Investigation," MIS Quarterly, vol. 22, no. 1, 1998, pp. 1-29.

[25] Janz, B. D., Wetherbe, J. C., Davis, G. B. et al., "Reengineering the Systems Development Process: The Link Between Autonomous Teams and Business Process Outcomes," Journal of Management Information Systems, vol. 14, no. 1, 1997, pp. 41-68.

[26] Karahanna, E., Xu, S. X., Xu, Y. et al., “The NeedsAffordances-Features Perspective for the Use of Social Media," MIS Quarterly, vol. 42, no. 3, 2018, pp. 737-756.

[27] Karasek, R. A., "Job Demands, Job Decision Latitude, and Mental Strain: Implications for Job Redesign," Administrative Science Quarterly, vol. 24, no. 2, 1979, pp. 285-308.

[28] Ke, W. and Zhang, P., "The Effects of Extrinsic Motivations and Satisfaction in Open Source Software Development," Journal of the Association for Information Systems, vol. 11, no. 12, 2010, pp. 784-808.

[29] King, W. R. and Sethi, V., "An Empirical Assessment of the Organization of Transnational Information Systems," Journal of Management Information Systems, vol. 15, no. 4, 1999, pp. 7-28. 
[30] Klesel, M., “A Conceptual Model for IT Work Autonomy (working paper)," University of Siegen, 2018.

[31] Klesel, M., Kampling, H., Bretschneider, U. et al., "Does the Ability to Choose Matter? On the Relationship between Bring Your Own Behavior and IT Satisfaction," Communications of the Association for Information Systems, vol. 43, 2018, pp. 690-710.

[32] Langfred, C. W., "Autonomy and Performance in Teams: The Multilevel Moderating Effect of Task Interdependence," Journal of Management, vol. 31, no. 4, 2005, pp. 513-529.

[33] Lee, G. and Xia, W., "Toward Agile: An Integrated Analysis of Quantitative and Qualitative Field Data on Software Development Agility," MIS Quarterly, vol. 34, no. 1, 2010, pp. 87-114.

[34] Liang, H., Peng, Z., Xue, Y. et al., "Employees' Exploration of Complex Systems: An Integrative View," Journal of Management Information Systems, vol. 32, no. 1, 2015, pp. 322-357.

[35] Liu, D., Li, X., and Santhanam, R., "Digital Games and Beyond: What Happens When Players Compete," MIS Quarterly, vol. 37, no. 1, 2013, pp. 111-124.

[36] MacKenzie, S. B., Podsakoff, P. M., and Podsakoff, N. P., "Construct Measurement and Validation Procedures in MIS and Behavioral Research: Integrating New and Existing Techniques," MIS Quarterly, vol. 35, no. 2, 2011, pp. 293-334.

[37] Malhotra, Y., Galletta, D. F., and Kirsch, L. J., "How Endogenous Motivations Influence User Intentions: Beyond the Dichotomy of Extrinsic and Intrinsic User Motivations," Journal of Management Information Systems, vol. 25, no. 1, 2008, pp. 267-299.

[38] Maruping, L. M., Venkatesh, V., and Agarwal, R., “A Control Theory Perspective on Agile Methodology Use and Changing User Requirements," Information Systems Research, vol. 20, no. 3, 2009, pp. 377-399.

[39] Mazmanian, M., Orlikowski, W. J., and Yates, J., "The Autonomy Paradox: The Implications of Mobile Email Devices for Knowledge Professionals," Organization Science, vol. 24, no. 5, 2013, pp. 1337-1357.

[40] Mirchandani, D. A. and Lederer, A. L., "Autonomy and Procedural Justice in Strategic Systems Planning," Information Systems Journal, vol. 24, no. 1, 2014, pp. 29 59.

[41] Mishra, A. N., Anderson, C., and Agarwal, R., "Electronic Health Records Assimilation and Physician Identity Evolution: An Identity Theory Perspective," Information Systems Research, vol. 23, no. 3, 2012, pp. 738-760.
[42] Moore, J. E., "One Road to Turnover: An Examination of Work Exhaustion in Technology Professionals," MIS Quarterly, vol. 24, no. 1, 2000, pp. 141-168.

[43] Morris, M. G. and Venkatesh, V., "Job Characteristics and Job Satisfaction: Understanding the Role of Enterprise Resource Planning System Implementation," MIS Quarterly, vol. 34, no. 1, 2010, pp. 143-161.

[44] Murray, K. B. and Häubl, G., "Freedom of Choice, Ease of Use, and the Formation of Interface Preferences," MIS Quarterly, vol. 35, no. 4, 2011, pp. 955-976.

[45] Nidumolu, S. R. and Subramani, M. R., "The Matrix of Control: Combining Process and Structure Approaches to Managing Software Development," Journal of Management Information Systems, vol. 20, no. 3, 2003, pp. 159-196.

[46] Ozer, M. and Vogel, D., "Contextualized Relationship Between Knowledge Sharing and Performance in Software Development," Journal of Management Information Systems, vol. 32, no. 2, 2015, pp. 134-161.

[47] Pan, Y., Huang, P., and Gopal, A., "Board Independence and Firm Performance in the IT Industry: The Moderating Role of New Entry Threats," MIS Quarterly, vol. 42, no. 3, 2018, pp. 979-1000.

[48] Rivard, S., Lapointe, L., and Kappos, A., “An Organizational Culture-Based Theory of Clinical Information Systems Implementation in Hospitals," Journal of the Association for Information Systems, vol. 12, no. 2, 2011, pp. 123-162.

[49] Roberts, N., Campbell, D. E., and Vijayasarathy, L. R., "Using Information Systems to Sense Opportunities for Innovation: Integrating Postadoptive Use Behaviors with the Dynamic Managerial Capability Perspective," Journal of Management Information Systems, vol. 33, no. 1, 2016, pp. 45-69.

[50] Rodon, J. and Silva, L., "Exploring the Formation of a Healthcare Information Infrastructure: Hierarchy or Meshwork?," Journal of the Association for Information Systems, vol. 16, no. 5, 2015, pp. 394-417.

[51] Ryan, R. M. and Deci, E. L., "Self-Determination Theory and the Facilitation of Intrinsic Motivation, Social Development, and Well-Being," American Psychologist, vol. 55 , no. 1,2000 , pp. $68-78$.

[52] Sanders, G. L. and Courtney, J. F., "A Field Study of Organizational Influencing DSS Success," MIS Quarterly, vol. 9, no. 1, 1985, pp. 77-93.

[53] Schein, E. H., Career Anchors: Discovering Your Real Values, University Associates, San Diego, 1985.

[54] Trevelyan, R., "The Paradox of Autonomy: A Case of Academic Research Scientists," Human Relations, vol. 54, no. 4, 2001, pp. 495-525. 
[55] Tripp, J., Riemenschneider, C., and Thatcher, J. B., "Job Satisfaction in Agile Development Teams: Agile Development as Work Redesign," Journal of the Association for Information Systems, vol. 17, no. 4, 2016, pp. 267-307.

[56] Vickery, C. M., Clark, T. D., and Carlson, J. R., "Virtual Positions: An Examination of Structure and Performance in Ad Hoc Workgroups," Information Systems Journal, vol. 9, no. 4, 1999, pp. 291-312.

[57] vom Brocke, J., Simons, A., Niehaves, B. et al., "Reconstructing the Giant: On the Importance of Rigour in Documenting the Literature Search Process," in Proceedings of the 17th European Conference on Information Systems, Paper 161, 2009.

[58] vom Brocke, J., Simons, A., Riemer, K. et al., "Standing on the Shoulders of Giants: Challenges and Recommendations of Literature Search in Information Systems Research," Communications of the Association for Information Systems, vol. 37, no. 1, 2015, pp. 205-224.

[59] Wastell, D. G., "Information Systems and EvidenceBased Policy in Multi-Agency Networks: The MicroPolitics of Situated Innovation," The Journal of Strategic Information Systems, vol. 15, no. 3, 2006, pp. 197-217.

[60] Webster, J. and Watson, R. T., "Analyzing the Past to Prepare for the Future: Writing a Literature Review," MIS Quarterly, vol. 26, no. 2, 2002, pp. xiii-xxiii.

[61] Ye, H. J. and Kankanhalli, A., "Solvers' Participation in Crowdsourcing Platforms: Examining the Impacts of Trust, and Benefit and Cost Factors," The Journal of Strategic Information Systems, vol. 26, no. 2, 2017, pp. 101-117.

[62] Ye, H. J. and Kankanhalli, A., "User Service Innovation on Mobile Phone Platforms: Investigating Impacts of Lead Userness, Toolkit Support, and Design Autonomy," MIS Quarterly, vol. 42, no. 1, 2018, pp. 165 187. 